\title{
Abnormal Blood Chemistry and Hematology Test Result
}

National Cancer Institute

\section{Source}

National Cancer Institute. Abnormal Blood Chemistry and Hematology Test Result. NCI Thesaurus. Code C35553.

A laboratory test result that indicates the presence of abnormal blood chemistry and/or hematology values. 